\title{
Catch-quota balancing in mixed-fisheries: a bio-economic modelling approach applied to the New Zealand hoki (Macruronus novaezelandiae) fishery
}

\author{
Paul Marchal ${ }^{1,2, a}$, Chris Francis ${ }^{3}$, Philippe Lallemand $^{2}$, Sigrid Lehuta $^{4}$, Stéphanie Mahévas ${ }^{4}$, \\ Kevin Stokes ${ }^{2}$ and Youen Vermard ${ }^{4}$ \\ 1 IFREMER, Channel and North Sea Fisheries Department, 150 Quai Gambetta, BP 699, 62321 Boulogne-sur-Mer, France \\ 2 Seafood Industry Council, 74 Cambridge Terrace, Wellington, New Zealand \\ 3 NIWA, 301 Evans Bay Parade, Hataitai, Wellington 6021, New Zealand \\ ${ }^{4}$ IFREMER, Fisheries and Ecological Modeling Department, Rue de l'Ile d'Yeu, BP 21105, 44311 Nantes Cedex 03, France
}

Received 16 December 2008; Accepted 19 May 2009

\begin{abstract}
Managing adequately the exploitation of commercial species subject to technical interactions is a key step towards the ecosystem approach to fisheries. We evaluate here, using a bio-economic modelling approach building on the ISIS-Fish simulation platform, the relative impact of total allowable commercial catches (TACC) and of taxes applicable to over-quota landings (deemed value) on the sustainability of a selection of species exploited by the New Zealand hoki (Macruronus novaezelandiae) fishery. We investigate some aspects of the hoki mixed fisheries, consisting of four fleets and nineteen métiers, by considering the technical interactions between hoki and Southern hake (Merluccius australis). The dynamics of effort allocation were modelled using gravity model, using value per unit of effort (VPUE) as attractivity coefficient. Several management scenarios, based on different levels of TACC, effort limits and deemed value have been defined. The impact of these strategies on spawning biomass and catches has been investigated. The results confirm that the deemed value may, in combination with TACC, be an efficient management tool. By increasing the hoki deemed value, we could somehow limit the decrease in the hoki TACC needed to harvest Western hoki sustainably. Constraining hoki fishing also restricts Southern hake fishing in the Chatham Rise and in the West Coast South Island, but leads to increased targeting of this species in the Sub-Antarctic area. The relative costs of renting/buying quota or paying the deemed value are most constraining when the hoki TACC is at relatively low level and when the hoki deemed value is more than 1.5 times the current value.
\end{abstract}

Key words: Fleet dynamics / New Zealand hoki fishery / Deemed value / Fisheries management

Résumé - La gestion adéquate de l'exploitation d'espèces commerciales sujettes à des interactions techniques constitue un premier pas dans la direction de l'approche écosystémique des pêches. Nous évaluons ici, au moyen d'une approche de modélisation bio-économique s'appuyant sur la plate-forme de simulation ISIS-Fish, l'impact relatif du total admissible de captures commerciales (TACC) et de taxes appliquées aux débarquements « hors quota » (taxes sur leur valeur estimée), sur la conservation d'une sélection d'espèces exploitées par la pêcherie de hoki (Macruronus novaezelandiae) néo-zélandaise. Nous étudions certains aspects de la pêcherie mixte de hoki, représentée par quatre flottilles et dix-neuf métiers, en considérant les interactions techniques entre le hoki et le merlu austral (Merluccius australis). La dynamique de l'allocation de l'effort de pêche a été modélisée en utilisant un modèle de gravité, dans lequel la valeur par unité d'effort (VPUE) représente le coefficient d'attractivité. On a défini plusieurs scénarios de gestion, basés sur différents niveaux de TACC, de limitation d'effort de pêche et de la taxe. L'impact de ces stratégies sur la biomasse féconde et les captures a été étudié. Les résultats confirment que la taxe, combinée avec les TACC, peut être un outil de gestion efficace. Il serait possible, en augmentant la taxe sur le hoki, de limiter dans une certaine mesure la réduction du TACC de hoki requise pour exploiter durablement le stock occidental de cette espèce. En limitant la pêche de hoki, on contraint également l'exploitation du merlu austral sur le plateau de Chatham et sur la côte occidentale de l'île du Sud mais cela conduit à un ciblage accru de cette espèce dans la zone sub-antarctique. Les coûts relatifs de location/achat de quota ou de paiement de la taxe sont plus contraignant lorsque le TACC de hoki est relativement bas et lorsque cette taxe appliquée au hoki dépasse 1,5 fois la valeur actuelle.

\footnotetext{
a Corresponding author: paul .marchal@i fremer.fr
} 


\section{Introduction}

Managing fisheries through individual property rights finds its roots in the early 1970s (Arnason 2007). Three main instruments have been envisaged: territorial user rights in fisheries (TURF), individual transferable efforts (ITE) and individual transferable quotas (ITQ). Of these three management instruments, the ITQ have had the broadest applicability, and have now been broadly implemented, including in 10 major fishing nations, to regulate around $15 \%$ of the global marine fish catch (12 million tonnes) (Arnason 2007).

In theory, ITQ create incentives for fishers to maximize the value of their catch and minimize harvest costs (Hentrich and Salomon 2006; Arnason 2007). They also create, in principle, economic incentives to avoid catching fish above quota. Finally, in mixed fisheries, ITQ are expected to alleviate the discrepancy between the combined-stocks quota portfolios and the actual species composition. Despite the flexibility brought about by ITQ, it is almost inevitable that the discrepancy will persist (Annala et al. 1991; Branch et al. 2006). A technical fix is then needed to correct that mismatch, that may take different forms depending on the country where the ITQ are implemented (Sanchirico et al. 2006).

In New Zealand, fisheries have been regulated by the quota management system (QMS) since 1986. A total allowable catch (TAC) is set by the Minister of Fisheries for each stock included in the QMS at the start of the fishing year. For most of these stocks, the fishing year starts on 1 October and finishes on 30 September in the following year. After an allocation has been granted to the recreational and the customary sectors, and also after provision has been made to account for other sources of mortality (mainly illegal fishing), the rest of the TAC (referred to as total allowable commercial catch, or TACC) is allotted to the commercial fishing sector. The TACC are then distributed to quota holders as ITQ shares, and an ACE (annual catch entitlement) is generated for each of them:

$$
\mathrm{ACE}(\mathrm{kg})=\mathrm{TACC}(\mathrm{kg}) \times \operatorname{ITQ}(\%)
$$

An ACE, like an ITQ, is freely tradable on the open market and accessible to any New Zealand citizen. Despite that flexibility, and even where fishers are allowed to acquire catch rights after landing fish, the aggregate commercial catch for the various stocks may not always match up with the TACC agreed for these stocks. Discarding is prohibited in New Zealand for almost all species managed under the quota management system (QMS) and therefore cannot be considered as an alternative to landing catch in excess of ACE holding as, e.g., in The Netherlands. However, as in many fisheries worldwide, misreporting is believed to occur in the hoki fishery (Bremner et al. 2009). In principle, New Zealand's fishers and/or quota-holders have two options: if landings are below ACE holding, quota-holders are allowed to carry forward up to $10 \%$ of their unused ACE into the next fishing year. On the other hand, if landings exceed their ACE holdings, fishers are allowed to land the portion of catch in excess of their ACE, even when the overall TACC for these species has already been exceeded. In that case, fishers are charged at the end of the fishing year a landing penalty, or "deemed value", for each unit of catch they land above their ACE holdings at the time. The deemed value is set annually by the Minister of Fisheries, at the same time as the TAC and the TACC. There is no clear policy or rationale as to how the deemed value is calculated. However, the level at which the deemed value is set may impact substantially the conservation of the harvested species. While a high deemed value (i.e. well above the ACE price) may encourage fishers to shift target species once their ACE is reached, a deemed value set too low may incentivise fishers to pay the penalty and continue targeting the same stock, even when they do not possess any ACE at all. Managing optimally fleets that harvest a mix of commercial species is a long-standing challenge for decisionmakers and their scientific advisors (Reeves et al. 2008). This challenge lies in an area somewhere between current singlespecies management and a fully comprehensive ecosystembased management. The main purpose of our approach is to evaluate, using a bio-economic modelling approach building on the ISIS-Fish software (http://www.ifremer.fr/isis-fish), the impact of relative TACC and deemed value on the sustainability of a selection of species exploited by the New Zealand hoki fishery. We will also discuss the extent to which this approach, and the issues it may raise, could be generalised in the broader context of ecosystem-based fisheries management.

\section{Material and methods}

\subsection{Base fishery model}

A number of fisheries simulation tools have been developed in the last twenty years, but these are based on either static effort allocation models (e.g., Walters et al. 1999), models that are not spatially-explicit (e.g., Ulrich et al. 2007), or models that were tailored to a particular fishery and cannot be easily transposed to another context (e.g., Holland 2000).

The bio-economic model used in this study is based on version 3.1.3 of ISIS-Fish (Mahévas and Pelletier 2004, Pelletier and Mahévas 2005). ISIS-Fish is a generic, spatially and seasonally explicit simulation tool for evaluating the impact of management measures on fisheries dynamics. The model allows for comparing the impacts of conventional input-output controls such as effort and catch limits, as well as any management measure with spatial implications. ISIS-Fish was designed to be reasonably generic, so it could be applied to different types of fisheries. Knowledge about each fishery may be stored in a database included with the software which can be easily updated. This includes the parameters describing each population and each fishing activity. ISISFish allows for various model assumptions (for instance stockrecruitment relationships, selectivity models, fleet dynamics etc.). Management measures, adaptive management as well as fisher's response to management and economic changes may be implemented through a Script language.

We summarise here the main features of ISIS-Fish. The full details and equations implemented in ISIS-Fish may be found in Mahévas and Pelletier (2004), Pelletier and Mahévas (2005) and Drouineau et al. (2006). ISIS-Fish is designed to assess the performance of local and temporal management measures involving spatial and seasonal control variables for regulating exploitation, e.g. fishing effort and catch. It is based on three sub-models, namely a population dynamics model, 
a fishing activity model and a model for management measures. Each sub-model is spatially and seasonally explicit. The biological sub-model is determined by a growth curve, condition factors, catchability coefficients, migration ogives and a recruitment function. The fishing activity sub-model builds on fleet parameters (fishing effort, economics), métier parameters (seasonal and spatial distribution of effort, selectivity ogives, an effort standardization factor, target factors) and strategy parameters (set of métiers, proportion of fishing units per fleet, and monthly distribution of fishing units among the métiers operated). Note that the standardization factor is used to get comparable effort measurement between gears, while the target factor associated with each species is an indicator of how strongly the species is targeted by a given métier. Finally, the management sub-model includes a series of management measures (TAC, mesh size limits, area access restrictions) and a fishers' behaviour gravity model. The gravity model (Caddy 1975 ) is used to quantify the relative attractivity of the different métiers, based on some utility variable (e.g., expected catch rate or profit).

The fishery takes place in a region defined by its boundary and a regular grid. The spatial resolution of the grid expressed in latitude and longitude is chosen with respect to the dynamics being described, and depends on the precision of available information. Within the region, zones (i.e. sets of contiguous grid cells) are defined independently for each population, each fishing activity and each management measure. The model has a monthly time step. Seasons (i.e. sets of successive months) are also defined independently for each population, each fishing activity and each management measure. Within each zone and season, relevant variables such as fishing effort for a specific activity or abundance of a given population, are assumed to be homogeneous and uniformly distributed.

\subsection{Data}

The New Zealand exclusive economic zone is partitioned in 10 fishery management areas (FMA) (Fig. 1). FMA 10 has mainly been established to prevent misreporting, as this area is normally subject to very little fishing activity and is not dealt with in the next sections. Today, 629 fish stocks are managed under the QMS. The management areas specific to each stock are referred to as the quota management areas (QMA), and they usually consist of 1 or a combination of several FMAs. However, the QMA of some aggregative species (e.g., orange roughy, oreos) may consist of sub-divisions of FMA. It should also be noted that the QMA, which are defined for management purposes, may occasionally be different from the stock areas defined for assessment purposes.

The hoki fishery (also known as the middle-depth fishery) is the largest fishery in New Zealand, mainly operated by bottom and mid-water trawlers. There are four main fisheries, two taking place on hoki spawning grounds (West Coast South Island and Cook Strait) and the others on hoki feeding grounds (Chatham Rise and Sub-Antarctic). Hoki is assessed as two separate stocks, an eastern component covering FMA 1 and 2, and a western component covering FMA 3 to 9 (Fig. 1). Although hoki is managed as one single stock
(HOK1), which covers FMA 1 to 9, an informal agreement between the New Zealand Ministry of Fisheries and the fishing industry has established a TACC allocation key between the eastern and the western stocks. In response to a series of poor recruitments, the overall hoki TACC dropped from $250000 \mathrm{t}$ (1986-87) to $180000 \mathrm{t}$ (2003-04), and again to $100000 \mathrm{t}$ in 2004-05 (Annala et al. 2004). Depending on where and when fishing is taking place, a number of by-catch species are caught in variable proportions in the hoki fishery, and these include in particular barracouta (Thyrsites atun), Southern hake (Merluccius australis), jack mackerels (Trachurus sp.), ling (Genypterus blacodes), orange roughy (Hoplosthetus atlanticus), oreos (Pseudocyttus maculatus, Neocyttus rhomboidalis and Allocyttus sp.), red cod (Pseudophycis bachus), southern blue whiting (Micromesistius australis), squids (Nototodarus sp.) and warehous (Seriolella sp.).

In this study, we investigate some aspects of the hoki mixed fisheries by considering the technical interactions between hoki and hake. Hake is not necessarily the most important by-catch species of the hoki fishery. However, because of its relatively high deemed value, hake may have practically constrained the hoki fishery in recent years whenever the hake TACC was exceeded.

Since 1989, Hoki (HOK1) has been assessed as two stocks, Eastern hoki (covering FMA 1-2) and Western hoki (covering FMA 3-9) (Francis 2007). Hake is managed and assessed as three stocks. The largest hake stock is found on the West Coast of the South Island (FMA 7) and it is referred to as HAK7. The two other stocks, which are located in FMA 1-3, 5-6, 8-9 (Sub-Antarctic hake or HAK1) and in FMA 4 (Chatham Rise hake or HAK4), are mainly by-catch of the hoki trawlers (Anon. 2007). For the five stocks, we have used the data and outputs from the most recent validated assessments, which were performed using the CASAL package (Bull et al. 2005).

Three runs were considered as equally valid, in the 2007 hoki stock assessment (Francis 2007). We selected the run which best fitted the requirements of the ISIS-Fish model used in this paper. The selected run assumed that the spawning fishery had a dome-shaped age-based selectivity, (2) no differentiation between males and females and, (3) natal fidelity (i.e. the fish to which a stock belongs is determined at birth) and the full independence between the two hoki stocks. Compared with the two other runs, the one we selected results in more optimistic stock assessment and projections for Western hoki, but is more pessimistic for Eastern hoki (Francis 2007).

The catch and effort data used to parameterise the exploitation sub-model were derived from mandatory New Zealand log-books. Data were available by fishing trip and by statistical area.

The TACC set for the different hoki and hake stocks in recent years (Table 1) have been used to parameterise the management models.

Finally, we used in our model the landing prices, ACE prices and deemed values related to the hoki (HOK1) and hake (HAK1, HAK4, HAK7) stocks (Table 2). We used the 2003/2004 average figures, as hake landing price data in subsequent years were found unreliable. The deemed value of these stocks is based on a differential system which means that the deemed value varies depending on the amount of fish landed 


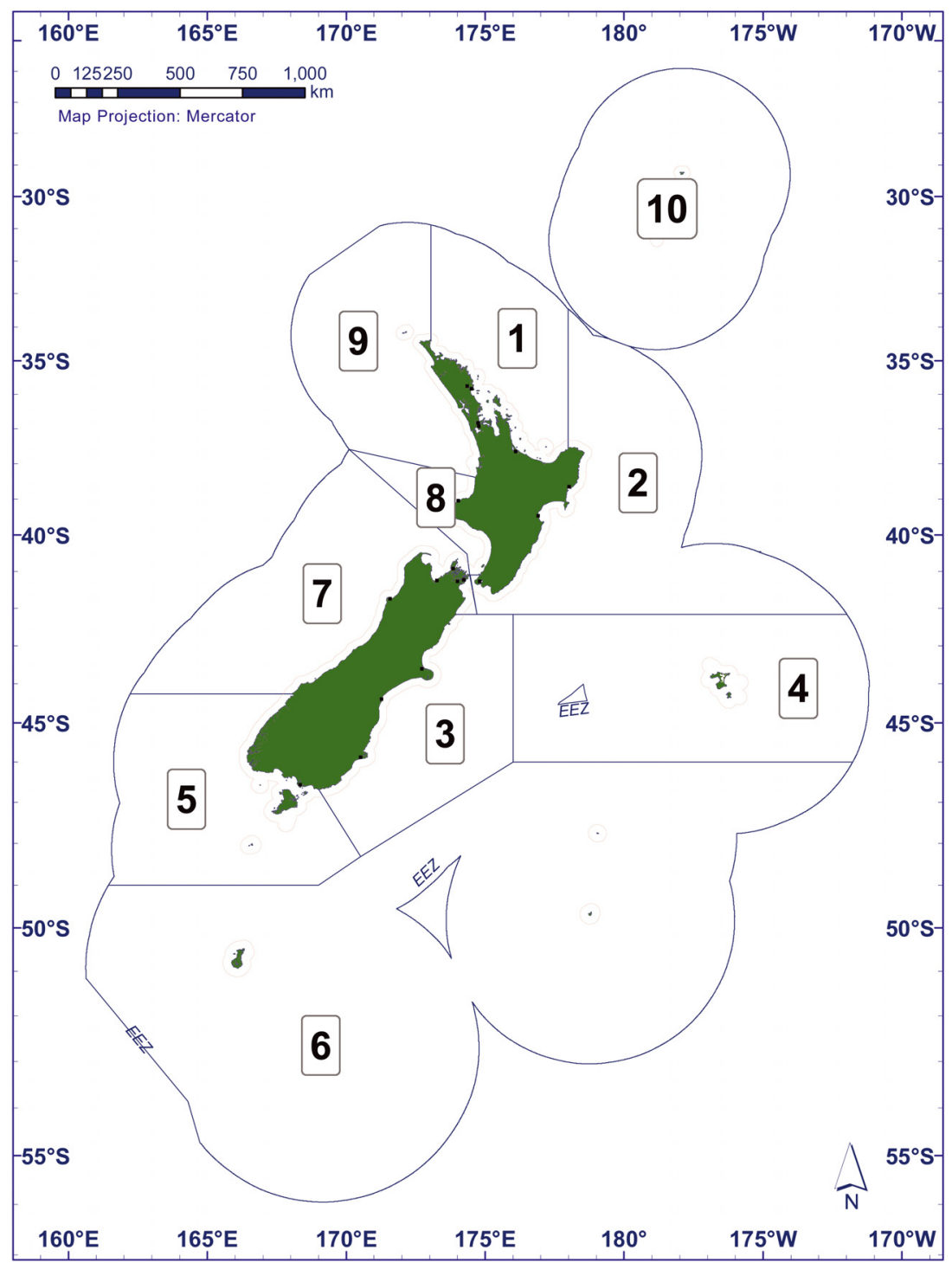

Fig. 1. Map of the New Zealand exclusive economic zone including fisheries management areas (FMA): (1) Auckland (East); (2) Central (East); (3) South-East Coast; (4) South-East (Chatham Rise); (5) Southland; (6) Sub-Antarctic; (7) Challenger/Central (Plateau); (8) Central (Egmont); (9) Auckland (West); (10) Kermadec.

Table 1. Total allowable commercial catch (TACC, in tonnes) set between fishing years 1996/1997 and 2005/2006 for hoki (Eastern and Western stocks confounded) and the three hake stocks (Sub-Antarctic hake, Chatham Rise hake, West Coast South Island hake). We consider that $60 \%$ and $40 \%$ of the hoki TACC applies to the Eastern and Western stock respectively.

\begin{tabular}{ccccc}
\cline { 2 - 5 } Period & hoki & $\begin{array}{c}\text { Sub-Antarctic } \\
\text { hake }\end{array}$ & $\begin{array}{c}\text { Chatham Rise } \\
\text { hake }\end{array}$ & $\begin{array}{c}\text { W. Coast } \\
\text { S. Island hake }\end{array}$ \\
\hline $1996 / 1997$ & 240000 & 3632 & 3500 & 6855 \\
$1997 / 1998$ & 250000 & 3632 & 3500 & 6855 \\
$1998 / 1999$ & 250000 & 3632 & 3500 & 6855 \\
$1999 / 2000$ & 250000 & 3632 & 3500 & 6855 \\
$2000 / 2001$ & 250000 & 3701 & 3500 & 6855 \\
$2001 / 2002$ & 200000 & 3701 & 3500 & 6855 \\
$2002 / 2003$ & 200000 & 3701 & 3500 & 6855 \\
$2003 / 2004$ & 180000 & 3701 & 3500 & 6855 \\
$2004 / 2005$ & 100000 & 3701 & 1800 & 6855 \\
$2005 / 2006$ & 100000 & 3701 & 1800 & 7700 \\
\hline
\end{tabular}


Table 2. Average landing price, annual catch entitlement (ACE) prices and deemed values (all in New Zealand dollars per kg of fish) obtained in fishing year 2003/2004 for hoki (Eastern and Western stocks confounded) and the three hake stocks (Sub-Antarctic hake, Chatham Rise hake, West Coast South Island hake). The deemed value shown here increases gradually in relation to the proportion of fish landed above the total allowable commercial catch (TACC).

\begin{tabular}{|c|c|c|c|c|c|c|c|c|}
\hline \multirow[t]{2}{*}{ Stock } & \multirow{2}{*}{$\begin{array}{l}\begin{array}{l}\text { Landing } \\
\text { price }\end{array} \\
\end{array}$} & \multirow{2}{*}{$\begin{array}{l}\mathrm{ACE} \\
\text { price }\end{array}$} & \multicolumn{6}{|c|}{ Deemed value by range of TACC exceeded } \\
\hline & & & $<20 \%$ & $20-40 \%$ & $40-60 \%$ & $60-80 \%$ & $80-100 \%$ & $>100 \%$ \\
\hline Hoki & 0.59 & 0.26 & 0.59 & 0.71 & 0.83 & 0.94 & 1.06 & 1.18 \\
\hline Sub-Antarctic hake & 1.52 & 0.82 & 1.17 & 1.40 & 1.64 & 1.87 & 2.11 & 2.34 \\
\hline Chatham Rise hake & 1.17 & 0.56 & 1.25 & 1.50 & 1.75 & 2.00 & 2.25 & 2.50 \\
\hline W.Coast S.Island hake & 1.82 & 1.19 & 1.38 & 1.66 & 1.93 & 2.21 & 2.48 & 2.76 \\
\hline
\end{tabular}

Table 3. Parameters characterizing growth, condition, natural mortality and recruitment of the hoki (Eastern hoki, Western hoki) and hake (Sub-Antarctic hake, Chatham Rise hake, West Coast South Island hake) stocks, as implemented in the bio-economic model.

\begin{tabular}{lcccccc}
\hline Stocks & Eastern hoki & Western hoki & $\begin{array}{c}\text { Sub-Antarctic } \\
\text { hake }\end{array}$ & $\begin{array}{c}\text { Chatham Rise } \\
\text { hake }\end{array}$ & $\begin{array}{c}\text { West Coast } \\
\text { South Island } \\
\text { hake }\end{array}$ \\
\hline No. age groups & & 17 & 17 & 7 & 7 & 7 \\
\hline \multirow{2}{*}{ Growth } & $L_{\propto}$ & 100.8 & 102.1 & 102.9 & 101.7 & 97.3 \\
& $k$ & 0.164 & 0.206 & 0.226 & 0.224 & 0.251 \\
\hline Condition factors & $a$ & $4.79 \times 10^{-6}$ & $4.79 \times 10^{-6}$ & $2.91 \times 10^{-6}$ & $2.10 \times 10^{-6}$ & $2.04 \times 10^{-6}$ \\
\hline$W(\mathrm{~kg})=a L(\mathrm{~cm})^{b}$ & $b$ & 2.89 & 2.89 & 3.22 & 3.28 & 3.32 \\
\hline Natural mortality & $\mathrm{M}$ & 0.27 & 0.27 & 0.19 & 0.19 & 0.19 \\
\hline Recruitment & $\mathrm{R}$ & $3.38 \times 10^{8}$ & $4.69 \times 10^{8}$ & $4.80 \times 10^{6}$ & $2.04 \times 10^{6}$ & $6.77 \times 10^{6}$ \\
\hline
\end{tabular}

above ACE. The deemed value we used here in the management model is the charge paid by the fishers when the amount of fish landed exceed their ACE holdings within any of the following ranges: 0-20\%, 20-40\%, 40-60\%, 60-80\%, 80-100\%, $>100 \%$.

\subsection{Model parameterisation}

\section{Population dynamics}

The growth parameters, condition factors, natural mortality, recruitment, migration and spawning ogives of all hoki and hake stocks were drawn or derived from Dunn et al. (2006), Francis (2007) and Anonymous (2007). For hoki, the growth parameters, condition factors and natural mortality were provided for both sexes combined. For the hake stocks, however, these parameters were provided for each sex separately, and the values we used were derived as the average over both sexes (Table 3). Recruitment was calculated based on the value leading to the virgin biomass $\left(B_{0}\right)$, as estimated in the assessment reports (Table 3). Consistent with Francis (2007), we assumed that the hoki spawning stock biomass (SSB) for both stocks was simply the total biomass in the spawning area. Dunn et al. (2006) indicated that for all hake stocks, $50 \%$ of hake individuals were mature at 6-8 years. We assumed here a knife-edge spawning, so that all hake aged 1-6 were immature and all fish aged 7 and older were mature.

For the hoki stocks, we kept the same number of age groups used in the 2007 assessment (i.e. 17 age groups with the latter being a plus-group). For all hake stocks, we used 7 age groups instead of the 30 given in the assessment. This simplification results from: (1) only spawning stock biomass trends were available and, (2) spawners were assumed to consist of all fish aged 7 and above. Consequently, for all hake stocks, age group 7 was made a plus-group, for which the biomass corresponded exactly to the SSB.

Migrations have been evidenced for both hoki stocks, and these are accounted for in the stock assessment (Francis 2007). Fish from the Eastern stock spawn in Cook Strait (border between FMA 2 and 7, Fig. 1) originate from the Chatham Rise (FMA 4). The Western stock spawn in the west coast of the South Island (FMA 5 and 7) originate from the sub-Antarctic region (FMA 6). Soon after the spawning process, all juveniles migrate to the Chatham Rise. Under the natal fidelity assumption, which we considered here, the stock to which a fish belongs is determined at birth. At some stage before age 8, all Western juvenile hoki migrate back to the SubAntarctic region. The migration ogives are used for both hoki stocks (Table 4). It is uncertain whether migrations are occurring within or across hake stock areas (Anonymous 2007), and these have been neglected in this study.

We also used $\mathrm{B}_{\mathrm{MSY}}$ proxies to evaluate the properties of the different management scenarios. For Sub-Antarctic and Chatham Rise hake, we used the estimates of the biomass corresponding to the maximum average yield $\left(B_{\mathrm{MAY}}\right)$ given in the assessment report (i.e. $19810 \mathrm{t}$ for HAK1, $7500 \mathrm{t}$ for HAK4). No estimates of $\mathrm{B}_{\mathrm{MSY}}$ were available in the assessment reports for West Coast South Island hake (HAK7) and any of the hoki stocks. For HAK1 and HAK4, B $\mathrm{MSY}$ is about $29 \%$ of the virgin biomass, and we used the same proportion for HAK7, resulting in a $\mathrm{B}_{\mathrm{MSY}}$ of about $26300 \mathrm{t}$ for that stock. A slightly more precautionary $\mathrm{B}_{\mathrm{MSY}}$ proxy (35\% of virgin biomass) was chosen for both hoki stocks to reflect the higher natural mortality and 
Table 4. Migration ogives ( $\%$ of each age groups subject to migration) used in ISIS-Fish for the Eastern and Western hoki stocks. A: Eastern hoki, from Chatham Rise to Cook Strait on 1st July. B: Western hoki, from Chatham Rise to Sub-Antarctic on 1st April. C: Western hoki, from Sub-Antarctic to West Coast South Island on 1st July.

\begin{tabular}{cccc}
\hline Age & A & B & C \\
\hline 1 & 0.02 & 0.29 & 0.42 \\
2 & 0.19 & 0.11 & 0.60 \\
3 & 0.33 & 0.44 & 0.37 \\
4 & 0.34 & 0.33 & 0.41 \\
5 & 0.35 & 1.00 & 0.39 \\
6 & 0.37 & 1.00 & 0.47 \\
7 & 0.46 & 0.51 & 0.59 \\
8 & 0.63 & 1.00 & 0.60 \\
9 & 0.63 & 1.00 & 0.60 \\
10 & 0.63 & 1.00 & 0.60 \\
11 & 0.63 & 1.00 & 0.60 \\
12 & 0.63 & 1.00 & 0.60 \\
13 & 0.63 & 1.00 & 0.60 \\
14 & 0.63 & 1.00 & 0.60 \\
15 & 0.63 & 1.00 & 0.60 \\
16 & 0.63 & 1.00 & 0.60 \\
$17+$ & 0.63 & 1.00 & 0.60 \\
\hline
\end{tabular}

Table 5. List of the 19 métiers implemented in the bio-economic model. The fishing season is all year round, except in the Cook Strait where (a) non spawning hoki is targeted in October-May and (b) hoki spawners are targeted in June-September.

\begin{tabular}{cllc}
\hline FMA $^{*}$ & Fishing ground & $\begin{array}{l}\text { Hoki stock } \\
\text { partition }\end{array}$ & $\begin{array}{c}\text { Métier } \\
\text { code }\end{array}$ \\
\hline 1 & Chatham Rise & Non spawners & 1 \\
\hline 2 & Chatham Rise & Non spawners & 2 \\
\cline { 2 - 4 } & Cook Strait $^{a}$ & Non spawners & 3 \\
& $b$ & Spawners & 4 \\
\hline 3 & Chatham Rise & Non spawners & 5 \\
\cline { 2 - 4 } & Cook Strait $^{a}$ & Non spawners & 6 \\
& $b$ & Spawners & 7 \\
\cline { 2 - 4 } & Sub-Antarctic area & Non spawners & 8 \\
\hline 4 & Chatham Rise & Non spawners & 9 \\
\hline 5 & Sub-Antarctic area & Non spawners & 10 \\
\cline { 2 - 4 } & West Coast South Is. & Spawners & 11 \\
\cline { 2 - 4 } & Others & All & 12 \\
\hline 6 & Sub-Antarctic area & Non spawners & 13 \\
\hline 7 & Cook Strait ${ }^{a}$ & Non spawners & 14 \\
& $b$ & Spawners & 15 \\
\cline { 2 - 4 } & West Coast South Is. & Spawners & 16 \\
\cline { 2 - 4 } & Others & All & 17 \\
\hline 8 & All & All & 18 \\
\hline 9 & All & All & 19 \\
\hline
\end{tabular}

${ }^{*}$ Fisheries management area.

fluctuations of hoki relative to hake. As a result, the $B_{\mathrm{MSY}}$ proxy calculated for hoki was of $277200 \mathrm{t}$ for the Eastern stock and $422450 \mathrm{t}$ for the Western stock.

\section{Exploitation}

By combining the hoki fisheries identified by Francis (2007) and the FMA, we defined nineteen métiers (Table 5).
Age-selectivity ogives by groups of métier were given for the hoki stocks by Francis (2007). A simple knife-edge fishery selectivity ogive was used for the three hake stocks based on information included in Dunn et al. (2006) and Anonymous (2007). The age-selectivity ogives are implemented for the hoki and hake stocks (Table 6). The standardization and the target factors associated to the hake and hoki populations were estimated using a GLM:

$$
\log \left(\mathrm{CPUE}+10^{-8}\right)=\alpha_{\text {year }}+\beta_{\text {month }}+\gamma_{\text {métier }}+\varepsilon .
$$

The link function of the GLM is set to identity. The catch rates (CPUE) were aggregated over all fleets and vessels, and were calculated by species, statistical rectangle, target species, métier, month and fishing year. $\varepsilon$ is a random noise assumed to be normally distributed. $\alpha, \beta$ and $\gamma$ respectively refer to the year, month and métier effects. The year and month effects represent abundance dynamics, while the métier effect may be interpreted as a combination of standardization and target factors.

Four fleets (FL1, FL2, FL3 and FL4) were identified based on vessel size (trawlers below and above $46 \mathrm{~m}$ ) and their main fishing strategy as defined below. Two strategies have been identified in each vessel size group, S1 and S2 for trawlers below $46 \mathrm{~m}$ (defining fleets FL1 and FL2 respectively) and S3 and S4 for trawlers above $46 \mathrm{~m}$ (defining fleets FL3 and FL4 respectively). Each strategy consists of a monthly effort allocation among the 19 métiers. The strategies have been identified by applying a cluster analysis to each vessel size group separately, using the Ward method. The variables analysed were, for each month, the proportion of days at sea allotted to each métier in fishing year 2005/2006. Two clusters were selected for each vessel size group, each of them representing one strategy.

From the log-books analysis, we found that the average trip duration for the large trawler fleet composed of 42 vessels was of 33 days. However, we were constrained to reduce the average trip duration for that fleet from 33 to 28 days, as ISIS-Fish does not allow fishing trips to exceed one month. In order to keep aggregated fishing effort invariant, we balanced the decrease in fishing trip duration by increasing the number of large trawlers from 42 to 50 vessels.

\section{Catchability}

The catchability coefficient is interpreted as a conduit between the population and the exploitation. Seasonal catchability could not be inferred directly and estimates were derived from the equation:

$$
\begin{aligned}
& q(\text { stock, season, age })= \\
& \frac{F_{s q}(\text { stock, season, age })}{\sum_{\text {métiers }} S(\text { stock, métier, age }) \times E(\text { métier }) \times \exp \left(\hat{\gamma}_{\text {métier }}\right)}
\end{aligned}
$$

where $F_{\text {sq }}$ is the status quo fishing mortality (i.e., the average fishing mortality over recent fishing years), $S$ is the selectivity and $E$ is the number of days at sea, and $\hat{\gamma}_{\text {métier }}$ is the métier effect derived from Equation (1). 
Table 6. Selectivity ogives used in ISIS-Fish for the hoki and hake stocks by métier groups. The métier groups identified in relation to the hoki fishery consist of: Ensp (métiers no. 1, 2, 3, 5, 6, 9, 14), Wnsp (métiers no. 8, 10, 13), Esp (métiers no. 4, 7, 15), Wsp (métiers no. 11, 16) and others (métiers no. 12,17, 18, 19). The métiers numbers refer to Table 5.

\begin{tabular}{|c|c|c|c|c|c|c|c|c|}
\hline \multirow[t]{2}{*}{ Age } & \multicolumn{5}{|c|}{$\begin{array}{l}\text { Eastern and Western hoki stocks / } \\
\text { métier groups }\end{array}$} & \multirow{2}{*}{$\begin{array}{c}\text { Sub- } \\
\text { Antarctic } \\
\text { hake }\end{array}$} & \multirow{2}{*}{$\begin{array}{c}\text { Chatham } \\
\text { Rise } \\
\text { hake }\end{array}$} & \multirow{2}{*}{$\begin{array}{l}\text { West Coast } \\
\text { South Is. } \\
\text { hake }\end{array}$} \\
\hline & Ensp & Wnsp & Esp & Wsp & Others & & & \\
\hline 1 & 0.12 & 0.81 & 0.06 & 0.06 & 0.26 & 0.00 & 0.00 & 0.00 \\
\hline 2 & 0.42 & 0.86 & 0.17 & 0.17 & 0.40 & 0.00 & 1.00 & 0.00 \\
\hline 3 & 0.84 & 0.91 & 0.37 & 0.37 & 0.62 & 0.00 & 1.00 & 0.00 \\
\hline 4 & 1.00 & 0.94 & 0.64 & 0.64 & 0.81 & 1.00 & 1.00 & 1.00 \\
\hline 5 & 0.99 & 0.97 & 0.90 & 0.90 & 0.94 & 1.00 & 1.00 & 1.00 \\
\hline 6 & 0.97 & 0.99 & 1.00 & 1.00 & 0.99 & 1.00 & 1.00 & 1.00 \\
\hline 7 & 0.93 & 1.00 & 0.98 & 0.98 & 0.97 & 1.00 & 1.00 & 1.00 \\
\hline 8 & 0.89 & 0.99 & 0.92 & 0.92 & 0.93 & & & \\
\hline 9 & 0.83 & 0.94 & 0.84 & 0.84 & 0.86 & & & \\
\hline 10 & 0.77 & 0.87 & 0.73 & 0.73 & 0.77 & & & \\
\hline 11 & 0.70 & 0.76 & 0.61 & 0.61 & 0.67 & & & \\
\hline 12 & 0.63 & 0.64 & 0.49 & 0.49 & 0.56 & & & \\
\hline 13 & 0.56 & 0.52 & 0.38 & 0.38 & 0.46 & & & \\
\hline 14 & 0.49 & 0.41 & 0.28 & 0.28 & 0.37 & & & \\
\hline 15 & 0.42 & 0.31 & 0.20 & 0.20 & 0.28 & & & \\
\hline 16 & 0.36 & 0.22 & 0.14 & 0.14 & 0.22 & & & \\
\hline 17 & 0.30 & 0.15 & 0.09 & 0.09 & 0.16 & & & \\
\hline
\end{tabular}

\section{Initial fishing mortality and stock-at-age numbers}

Fishing mortality $(F)$ and stock numbers at age $(N)$ series were required to derive catchability coefficients and to initiate the simulations, and these were derived based on available information. For the hoki stocks, both abundance-at-age and catch-at-age by season were available from the 2007 assessment, and $F$ was calculated by solving the combined VPA and Baranov catch equations. $F_{\mathrm{sq}}$ was calculated as the fishing mortality averaged over fishing years 2003-04, 2004-05 and 2005-06. For the hake stocks, age- or season-based information could not be made available. Data available from the 2004 assessment included aggregated annual time series of SSB and catch. Consistent with the spawning ogive used in this paper, the hake SSB of all stocks corresponds exactly to the biomass of fish aged 7 and older. Based on the selectivity information given in Anonymous (2007) and Dunn et al. (2006), we assumed that fishing mortality was null over ages 1-3 and constant over ages 4-7 (HAK1 and HAK7), and null at age 1 and constant over ages 2-7 (HAK4). By combining the VPA and the Baranov catch equations, we could then derive the F/age and N/age matrices. $F_{\text {sq }}$ was calculated as the fishing mortality averaged over the past three years.

\section{Fleet dynamics}

The dynamics of the fleets were modelled using a gravity model (Caddy 1975) that calculates the relative attractivity of the different métiers. The expected value per unit of effort (VPUE) was chosen as the attractivity variable determining the effort allocation across métiers at each monthly time step, and that was estimated to be the VPUE obtained in the previous year and in the same month, assuming perfect information of the fleets. The VPUE was calculated as the landing value minus ACE rental cost (and/or the deemed value) divided by fishing effort. The effort allocation across métiers in the following month is then calculated as the proportion of expected VPUE by metier, and it varies dynamically over time. The overall nominal effort is always constant, except if all the metiers operated are expected to lead to a negative VPUE. In that case, fishing ceases in the following month and fishing effort is set to zero. In the first year of simulation, the base strategies are defined as S1 and S2 (small trawlers), S3 and S4 (large trawlers).

\section{Management strategy evaluation framework}

Our management strategy evaluation framework builds on various performance indicators. These indicators reflect:

1. Stock status: ratio between spawning biomass and $B_{\mathrm{MSY}}$ after 10 years of projection, frequency of spawning biomass falling below $B_{\mathrm{MSY}}$ during the 10 years projection period;

2. Exploitation levels: total catch averaged over 10 years of projection, ratio between total catch and TACC averaged over 10 years of projection, frequency of catches below TACC during the 10 year-projection period; and

3. Economics: total ACE cost and/or deemed value paid relative to total catch value, averaged over the 10 years' projection period.

We evaluated the impact of two management instruments applied to the New Zealand hoki fisheries: (i) the TACC (i.e. the commercial share of the overall TAC) and (ii) the deemed value, as applied to each hoki and hake stocks (Tables 1 and 2). TACC and deemed values were both set at the beginning of the simulation period for each stock. We proceeded with a threestep approach.

First, we evaluated the sensitivity of the model outputs to three parameters: hoki recruitment, hake recruitment and the type of fleet behaviour. To simplify the recruitment sensitivity analyses, we considered that all species stocks were subject 
to the same shift scale. For both hoki and hake recruitments, we looked at three potential scenarios: the base (or medium level) value (Table 3), the base value minus 50\% (low level) and the base value plus 50\% (high level). We also considered two fleet behaviour models: a dynamic (or base) model, where fishing effort is apportioned into métiers in proportion to the expected VPUE distribution, and a static (or traditional) one, where effort allocation is not subject to inter-annual variations. In total, 18 simulations (combining 3 hoki recruitment scenarios, 3 hake recruitment scenarios and 2 fleet behaviour models) were carried out in relation to the sensitivity analyses.

Second, we carried out a preliminary investigation of management strategies building on TACC, deemed value and fishing effort. For both TACC and deemed value, we looked at three potential scenarios: the current value (mean level or status quo), the current value minus 50\% (low level) and the current value plus $50 \%$ (high level). We also looked at the effects of increasing by $50 \%$ the current level of aggregate fishing effort.

Finally, we had a closer look at the impact of the hoki deemed value and TACC. To that purpose, we calculated the response of the management strategy performance indicators to a combination of hoki deemed value multipliers (ranging from 0.5 to 2 by 0.25 steps) and TACC multipliers (ranging from 0 to 2 by 0.25 steps). Each multiplier was applied to the base (status quo) values of the hoki deemed value and TACC shown in Tables 1 and 2.

\section{Results}

\subsection{Estimated exploitation parameters and catchability}

The métier effects from the GLM are shown in Table 7. The top four métiers as to hoki fishing are, by decreasing target factors, métiers 12 (fishing in other areas, FMA 5), 13 (fishing in Sub-Antarctic area, FMA 6), 16 (fishing hoki spawners in the West Coast South Island, FMA 7) and 9 (fishing nonspawning hoki in Chatham Rise, FMA 4). These four métiers also target hake to a large extent. Thus, the targeting factors associated to métiers $16,13,12$ and 9 are respectively ranked 2 to 5 by decreasing value. Métier 15 (fishing hoki spawners in the Cook Strait, FMA 7) targets hoki with almost no hake by-catch. Métier 10 (fishing non-spawning hoki in SubAntarctic area, FMA 5) is ranked first as to hake fishing and operates with limited hoki by-catch. Finally, métiers 1 (fishing in Chatham Rise, FMA 1), 2 (fishing in Chatham Rise, FMA 2), 3 (fishing non-spawning hoki in the Cook Strait, FMA 2), 17 (fishing in other areas, FMA 7) and 19 (fishing in other areas, FMA 9) have very low targeting factors for both hake and hoki, and these are clearly targeting other species.

The main characteristics of the four fleets are shown in Table 8, while the four strategies identified in this study are shown in Figure 2. Small trawlers may pursue two contrasting strategies. With strategy S1, most of the fishing effort is dedicated to métiers targeting mainly other species than hoki and hake (e.g., métiers 1 and 2 and, to a lesser extent, métiers 6 and 7). With that strategy, the most important métier in relation to hoki and hake fishing is métier 16. By contrast, with strategy S2, most of the fishing effort is allocated to métiers
Table 7. Hake and hoki (all stocks confounded). Métier effect derived from the Generalized Linear Model, which is here interpreted as the product of the standardization factor and of the target factor. The métiers numbers refer to Table 5 .

\begin{tabular}{crr}
\hline Métier & \multicolumn{2}{c}{ Métier effect } \\
\cline { 2 - 3 } code & Hake & Hoki \\
\hline 1 & 0.07 & 1.15 \\
2 & 0.10 & 3.03 \\
3 & 0.21 & 3.76 \\
4 & 0.08 & 38.80 \\
5 & 0.56 & 2.31 \\
6 & 0.49 & 6.68 \\
7 & 0.83 & 14.94 \\
8 & 4.24 & 2.01 \\
9 & 4.29 & 65.29 \\
10 & 11.14 & 19.40 \\
11 & 2.76 & 26.46 \\
12 & 7.23 & 149.26 \\
13 & 7.72 & 93.76 \\
14 & 1.93 & 28.14 \\
15 & 0.13 & 61.87 \\
16 & 7.86 & 65.34 \\
17 & 0.05 & 1.01 \\
18 & 1.97 & 6.28 \\
19 & 1.00 & 1.00 \\
\hline
\end{tabular}

Table 8. Main characteristics of the four fleets FL1, FL2, FL3 and FL4 investigated in the analysis, based on fishing year 2005/2006. The details of strategies S1, S2, S3 and S4 are given in Tables 9a and $9 \mathrm{~b}$.

\begin{tabular}{lllll}
\cline { 2 - 5 } & \multicolumn{4}{c}{ Fleet } \\
\cline { 2 - 5 } Main gear & FL1 & FL2 & FL3 & FL4 \\
\cline { 2 - 5 } & trawl & trawl & trawl & trawl \\
\hline Length range & $12-45 \mathrm{~m}$ & $12-45 \mathrm{~m}$ & $46-110 \mathrm{~m}$ & $46-110 \mathrm{~m}$ \\
\hline Mean trip duration & 4 days & 4 days & 28 days & 28 days \\
\hline Number of vessels & 133 & 16 & 22 & 28 \\
\hline Strategy & S1 & S2 & S3 & S4 \\
\hline
\end{tabular}

targeting hoki and hake (e.g., métiers 9 and 13), or hoki only (métier 15). With that strategy, the most important métier targeting other species than hoki and hake is métier 14. The contrast between the strategies pursued by the large trawlers is less obvious than for the small trawlers. With both strategies $\mathrm{S} 3$ and S4, the main métiers are targeting hoki and hake. The main difference between strategies is that more métiers may be selected with S3 than with S4.

Finally, the seasonal catchability estimates and the initial stock at age numbers for the hoki and hake stocks are shown in Tables 9 and 10, respectively.

\subsection{Management strategies evaluation}

Figure 3 shows the results of the sensitivity analyses for the five stocks being investigated. The impact of one species' (hoki or hake) recruitment on the other species' SSB and catch was null with the static behaviour model, and limited with the dynamic model. Therefore, Figures 3a-c show only the scenarios with medium (or base) hoki recruitment (scenarios 0 to 5), 

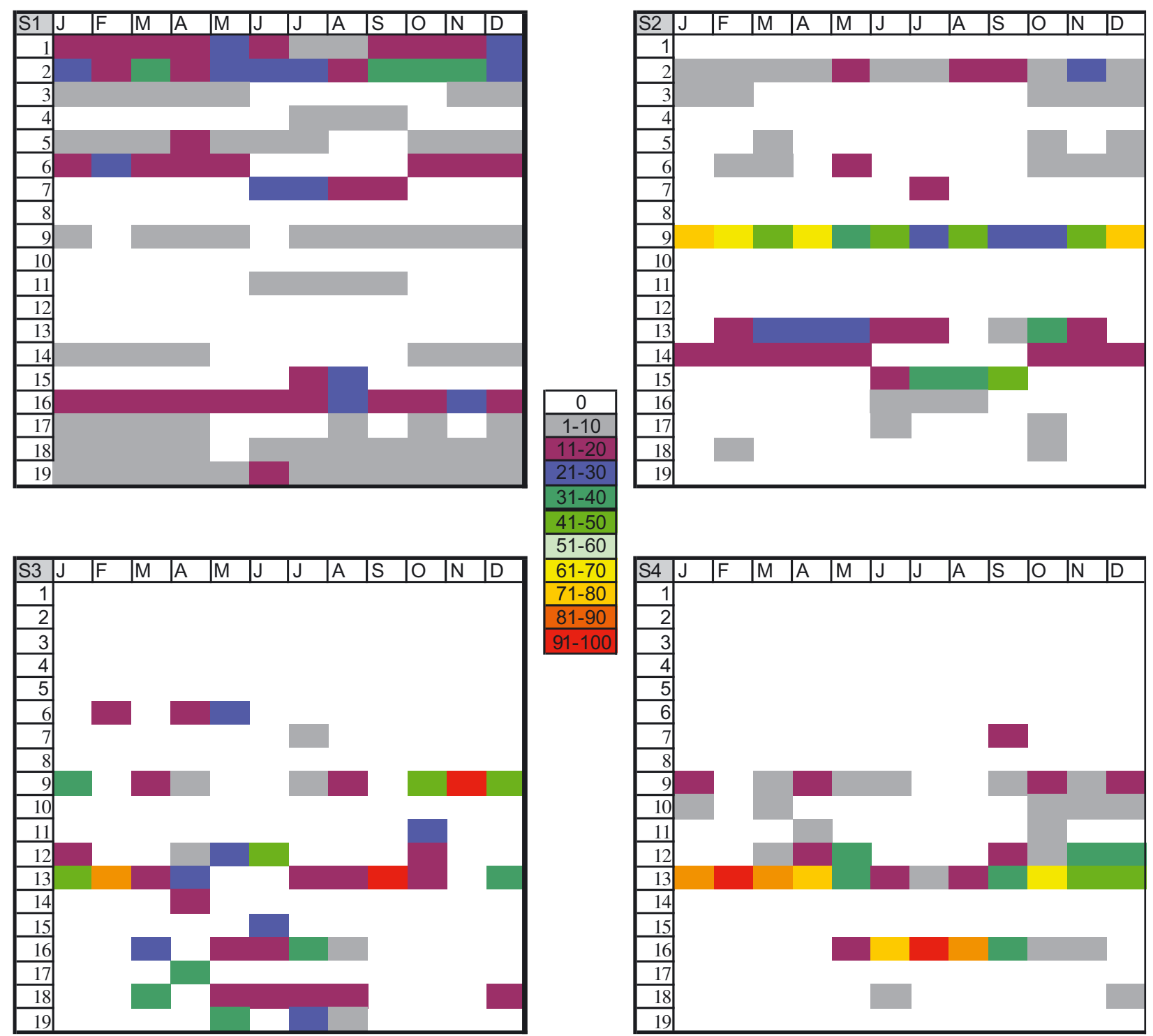

Fig. 2. Monthly effort allocation among métiers in strategies S1 to S4. The colours correspond to the percentage distribution of the effort in each month. The métier numbers (in column 1) refer to Table 5.

while Figures 3d-e show only the scenarios with medium (or base) hake recruitment (scenarios 0, 1, 6-9). Overall, the results suggest that the effects of recruitment and of fleet behaviour on both SSB and catch are of the same order of magnitude for all stocks. At low recruitment levels, the impact of the fleet behaviour model on both SSB and catch levels is rather limited, especially for Chatham Rise hake and Western hoki comparison of scenarios 4 and 5 (Figs. 3a-c) and of scenarios 8 and 9 (Figs. 3d-e). At medium and high recruitment levels, the fleet behaviour model impacts substantially the catches of SubAntarctic hake (Fig. 3a), the spawning biomass of Chatham Rise hake (Fig. 3b), and both the catches and SSB of Eastern and Western hoki (Figs. 3d,e).

Figure 4 (left hand side) shows the impact of the eleven management scenarios on the ratio between SSB and $B_{\mathrm{MSY}}$. The highest SSB levels are obtained with a low effort or a low hoki TACC strategy. Increasing the hoki deemed value increases the SSB of all stocks except Sub-Antarctic hake. However, that increase is not as marked as with the low effort and low hoki TACC scenarios. The lowest SSB levels appear with a low hoki deemed value, a high hoki TACC and/or a high effort. Increasing the hoki TACC decreases the SSB of all stocks except Eastern hoki. However, that decrease is not as marked as with the high effort and low hoki deemed value scenarios. Changes in the hake TACC and deemed value have little effect on the SSB of the stocks being investigated.

Figure 4 (right hand side) shows the impact of the eleven management scenarios on the ratio between total catches and TACC. Some scenarios (high effort, low hoki TACC, high hoki deemed value) lead to unstable catch oscillations. For all hake stocks, the worst TACC overshot (respectively the best compliance with TACC) results from a low (respectively high) hake TACC. For the Chatham Rise hake stock, most scenarios lead to a TACC overshot in year 10 (except with low hoki 
Table 9. Catchability-at-age coefficients $\left(\times 10^{-7}\right)$ of hoki and hake at different periods of the year (P1: October-November, P2: December-March, P3: April-June, P4: July-September).

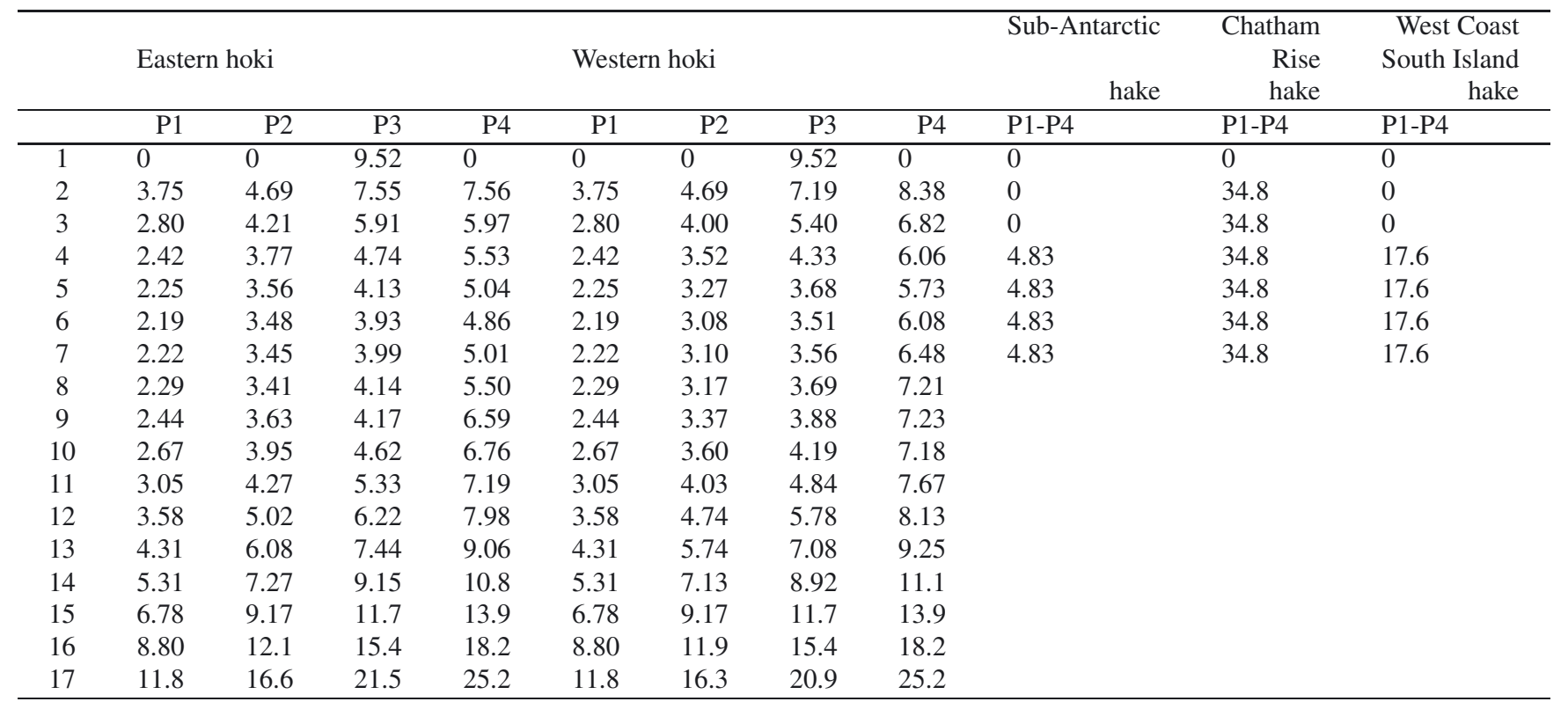

Table 10. Initial stock-at-age numbers (in million) as used in the simulations for hoki and hake.

\begin{tabular}{|c|c|c|c|c|c|c|c|c|}
\hline$\overline{\text { Age }}$ & \multicolumn{2}{|c|}{ Eastern hoki } & \multicolumn{3}{|c|}{ Western hoki } & \multicolumn{3}{|c|}{ Hake } \\
\hline & Chatham Rise & Cook Strait & Chatham Rise & Sub-Antarctic & $\begin{array}{l}\text { West Coast } \\
\text { South Island }\end{array}$ & Sub-Antarctic & Chatham Rise & $\begin{array}{l}\text { West Coast } \\
\text { South Island }\end{array}$ \\
\hline 1 & 0 & 0 & 0 & 0 & 0 & 4.80 & 2.04 & 6.77 \\
\hline 2 & 137.60 & 1.94 & 100.90 & 46.51 & 17.94 & 3.96 & 1.69 & 5.60 \\
\hline 3 & 184.80 & 32.12 & 89.43 & 35.23 & 28.25 & 3.28 & 1.18 & 4.63 \\
\hline 4 & 113.70 & 38.33 & 47.56 & 67.61 & 28.16 & 2.71 & 0.83 & 3.83 \\
\hline 5 & 66.16 & 22.51 & 35.57 & 71.97 & 33.75 & 2.10 & 0.58 & 2.78 \\
\hline 6 & 20.84 & 7.58 & 0 & 5.86 & 2.51 & 1.63 & 0.41 & 2.02 \\
\hline 7 & 44.13 & 17.27 & 0 & 13.74 & 7.80 & 7.33 & 1.66 & 8.46 \\
\hline 8 & 2.53 & 1.40 & 0 & 1.74 & 1.65 & & & \\
\hline 9 & 6.09 & 6.40 & 0 & 2.32 & 2.31 & & & \\
\hline 10 & 7.87 & 8.45 & 0 & 2.76 & 2.88 & & & \\
\hline 11 & 3.30 & 3.62 & 0 & 3.09 & 3.38 & & & \\
\hline 12 & 1.15 & 1.29 & 0 & 1.93 & 2.20 & & & \\
\hline 13 & 3.47 & 3.95 & 0 & 5.98 & 7.11 & & & \\
\hline 14 & 1.64 & 1.90 & 0 & 3.10 & 3.80 & & & \\
\hline 15 & 1.64 & 1.91 & 0 & 5.77 & 7.23 & & & \\
\hline 16 & 1.10 & 1.30 & 0 & 4.07 & 5.19 & & & \\
\hline 17 & 9.24 & 10.95 & 0 & 13.21 & 17.04 & & & \\
\hline
\end{tabular}

TACC and the high effort scenarios). For the Western hoki and Chatham Rise hake stocks, the TACC is always (Western hoki) or almost always (Chatham Rise hake) exceeded over the 10 -year period. For Eastern hoki, the worst TACC overshot results from a low hoki TACC, while both a high hoki TACC and a low effort generally maintain catches below TACC.

Figure 5 shows the effect of different combinations of hoki deemed value and TACC on two SSB indicators. The SSB of Sub-Antarctic hake, West Coast South Island hake and Eastern hoki is above $B_{\mathrm{MSY}}$ for all the management scenarios investigated, over the 10-year period (figures not shown here). The impact of the different management scenarios on the SSB of Western hoki and Chatham Rise hake are rather straightforward. Both the frequency of SSB above $B_{\mathrm{MSY}}$ and the ratio between SSB and $B_{\mathrm{MSY}}$ increase when the hoki TACC decreases and when the hoki deemed value increases. With the current hoki TACC and deemed value, the Western hoki SSB is expected to exceed $B_{\mathrm{MSY}}$ during $60 \%$ of the projected years. Increasing the deemed value does not provide clear benefits for that stock. If we aim at maintaining the SSB above $B_{\mathrm{MSY}}$ in at least $80 \%$ of the projected period, then there may be several options: either the TACC should be decreased to $50 \%$ of its current value (keeping the deemed value at status quo), or the TACC should be decreased to $80 \%$ of its current value whilst the hoki deemed value is increased by $30 \%$ above its current value. Either option would drive the Chatham Rise hake SSB 

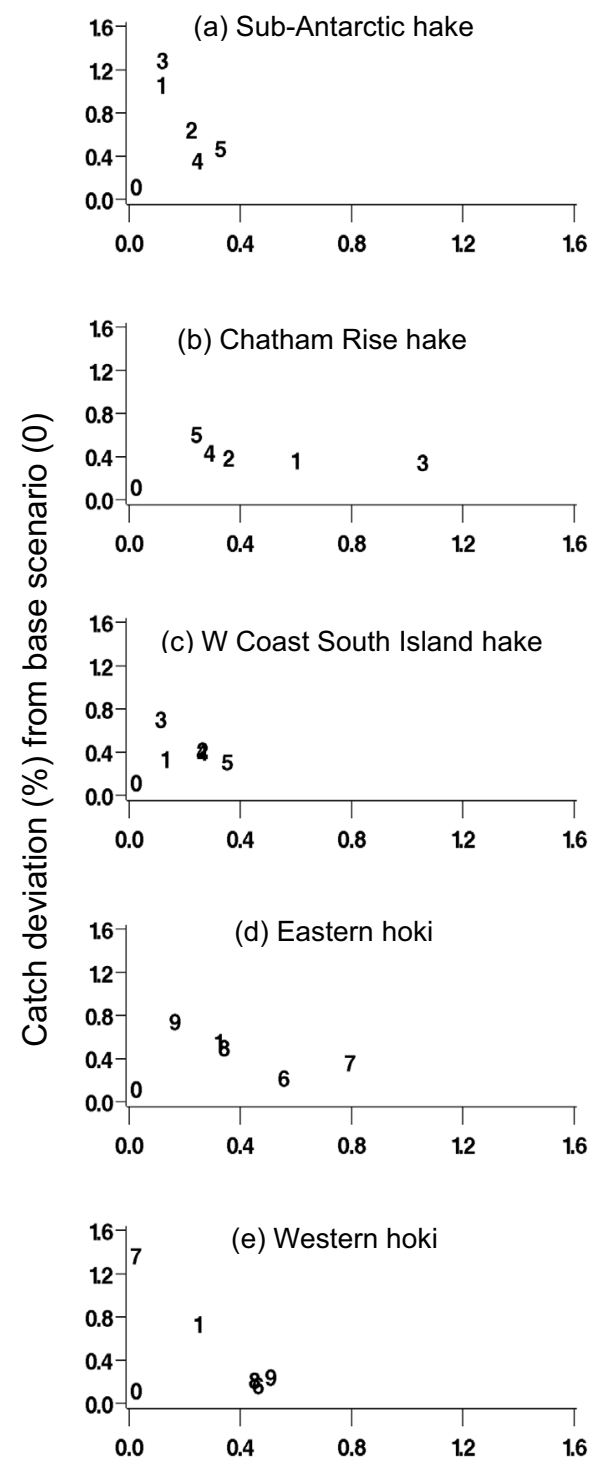

SSB deviation (\%) from base scenario (0)

Fig. 3. Sensitivity analyses for (a) Sub-Antarctic hake, (b) Chatham Rise hake, (c) West Coast South Island hake, (d) Eastern hoki, (e) Western hoki. Each scenario is defined by ["hoki recruitment level", "hake recruitment level", "effort allocation model"]. The Xaxis and the $Y$-axis show respectively the SSB and the catch deviations (\%) from the base scenario 0 defined by [medium, medium, dynamic]. The other scenarios shown are: 1 [medium, medium, static]; 2: [medium, high, dynamic]; 3 [medium, high, static]; 4 [medium, low, dynamic]; 5 [medium, low, static]; 6 [high, medium, dynamic]; 7 [high, medium, static]; 8 [low, medium, dynamic]; 9 [low, medium, static]. Scenarios 2 and 4, 1 and 8,6 and 8, overlap respectively for (c) West Coast South Island hake, (d) Eastern hoki, (e) Western hoki.

above $B_{\mathrm{MSY}}$ in $100 \%$ of the projected years. More generally inflating the constraints on the Western hoki fishery (either by decreasing the TACC or increasing the deemed value) also restricts fishing for the Chatham Rise hake stock. At status quo, hoki TACC and deemed value, both the hake and hoki SSB are expected to be around $B_{\mathrm{MSY}}$ or above after 10 years of projections.
Figure 6 shows the effect of different combinations of hoki deemed value and TACC on total catch. Increasing both the hoki TACC and deemed value results in an increase in the total catch of both hoki stocks, Chatham Rise hake and West Coast South Island hake (Figs. 7b-e). When the hoki TACC increases, the Sub-Antarctic hake catches decrease, reach a minimum, which is determined by the hoki deemed value, and then increase slightly (Fig. 7a). Increasing the hoki deemed value does not have marked effects on Sub-Antarctic hake catches.

Figure 7 shows the effect of different combinations of hoki deemed value and TACC on two exploitation indicators: (left) the frequency of catches maintained below TACC and (right) the catch-TACC ratio. Note that the hake TACC and deemed value are not varied here, so the results observed for hoki and hake should be interpreted differently.

Increasing the hoki TACC and decreasing the hoki deemed value result in a deterioration of the TACC compliance (represented by both a decrease in frequency of catches below TACC and an increase in the catch-TACC ratio indices) for Chatham Rise hake and West Coast South Island hake (Figs. 7b-c). Overall, increasing the hoki TACC enhances the compliance of the Sub-Antarctic hake fishery. Thus, the frequency of catches below TACC increases with the hoki TACC and is of $100 \%$ at current TACC levels, while average catches are below TACC, except when the hoki TACC is close to 0 (Fig. 7a). Increasing the hoki deemed value does not have marked effects on the compliance with TACC of the Sub-Antarctic hake fishery. Because the hake TACC are invariant, these results are consistent with the hake total catch trends (Figs. 6a-c), as one could have anticipated.

Increasing the hoki TACC improves the TACC compliance of the Eastern hoki fishery (Fig. 7d). When the hoki TACC is below current level, increasing the hoki deemed value also improves the TACC compliance of the Eastern hoki fishery. When the hoki TACC is above current level, increasing the hoki deemed value does not have marked effects on TACC compliance for the Eastern hoki fishery. For all management scenarios, the Western hoki TACC is overshot every year of the projection period, and it is not represented here.

Figure 8 shows the effect of different combinations of hoki deemed value and TACC on an economic index representing the ratio between the costs generated by ACE or deemed value payment and the total value of average catches. The impact of the hoki deemed value is relatively straightforward: the higher the hoki deemed value, the higher the economic index. When the hoki deemed value is below current level, changing the hoki TACC does not have a marked effect on the economic index (costs are about $50 \%$ of catch value). When the deemed value is above current level, increasing the hoki TACC first results in a steep increase of the relative costs, which reach a maximum and then decline. These results suggest that any reduction in the hoki TACC from current level should be accompanied by a substantial increase in the hoki deemed value to impact fishers' economics.

\section{Discussion}

The results presented in this paper may be of use for fisheries managers and scientists, particularly in a context of 

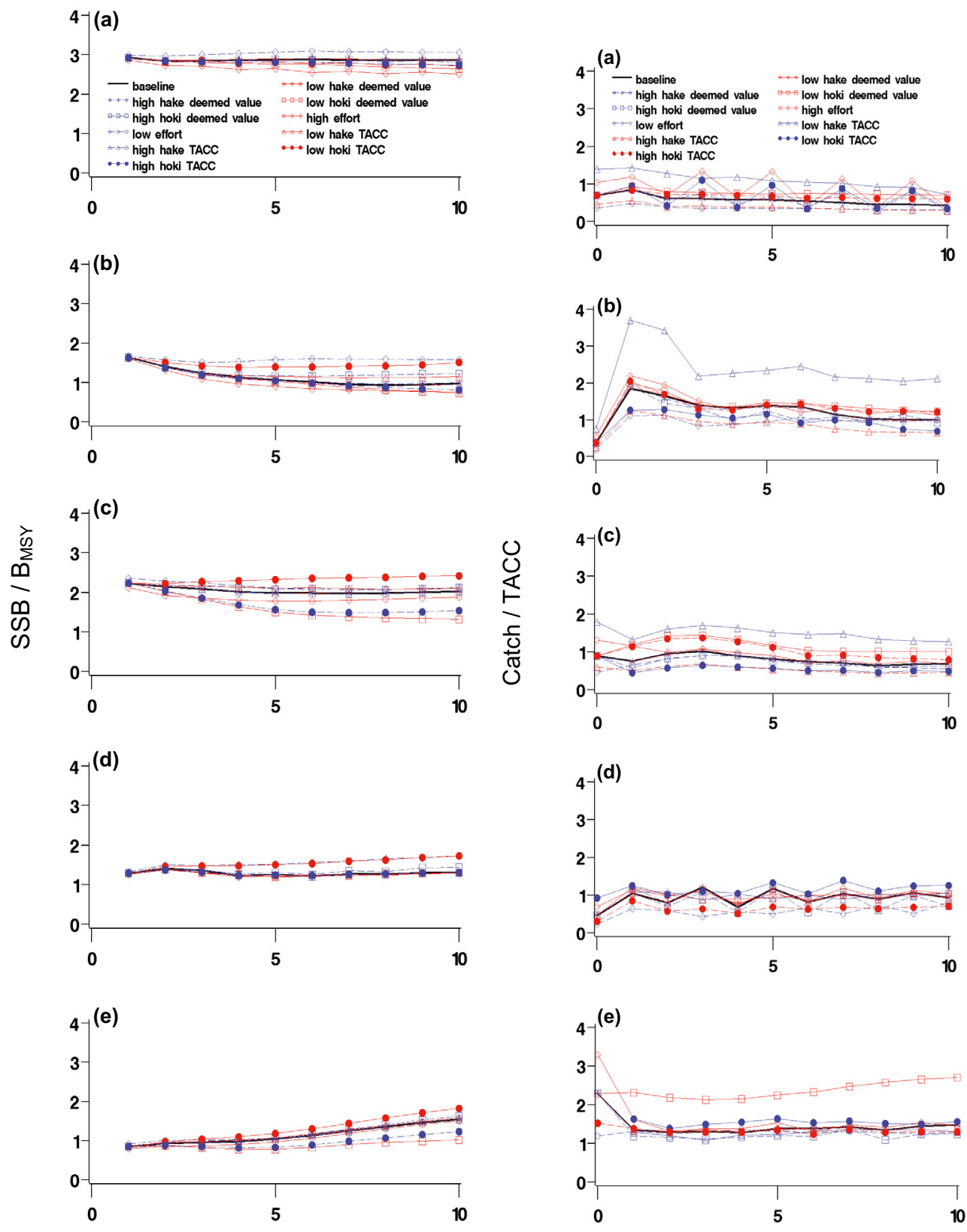

Fishing year

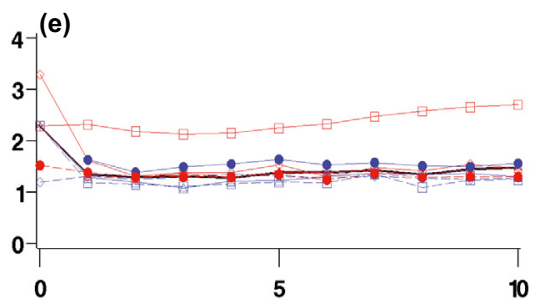

Fishing year

Fig. 4. Annual variations of the ratio ( $\mathrm{SSB} / \mathrm{B}_{\mathrm{MSY}}$ ) (left hand side) and annual variations of the ratio (catch/TACC) (right hand side) by simulation type and by stock: (a) Sub-Antarctic hake, (b) Chatham Rise hake, (c) West Coast South Island hake, (d) Eastern hoki, (e) Western hoki. The base management strategy (all TACC, deemed values and fishing efforts set to current value) is shown as a black bold line. The alternative management strategies and tools being investigated are: hoki TACC (dots), hoki deemed value (square), hake TACC (triangle), hake deemed value (star), fishing effort (diamond); low value in blue, high value in red for TACC and effort and vice versa for deemed value.

mixed fisheries. There is currently no scientific basis in New Zealand for setting the deemed value, and the approach we propose here could bring some elements in the process of calculating this parameter. Our results also confirm that the economic incentives, combined with appropriate catch limits, may be an appropriate management tool, which may complement other conservation measures. We could also quantify the combined effects of hoki catch limits and deemed value on the SSB and catch of hoki and hake, and also evaluate some economic properties of the various management scenarios investigated.
The outcomes of our sensitivity analysis indicated that assumptions made respectively on fleet dynamics and on population dynamics should be treated on an equal footing, which bears out some of the conclusions of Hilborn $(1985,2007)$. The results of our sensitivity analysis also suggest that, overall, the assumptions made on fleet dynamics are more critical when recruitment is large and hence not a limiting factor.

While both TACC and deemed values are management measures, they are of a different sort. TACC are conservation measures, and are set based on single-stock projections 

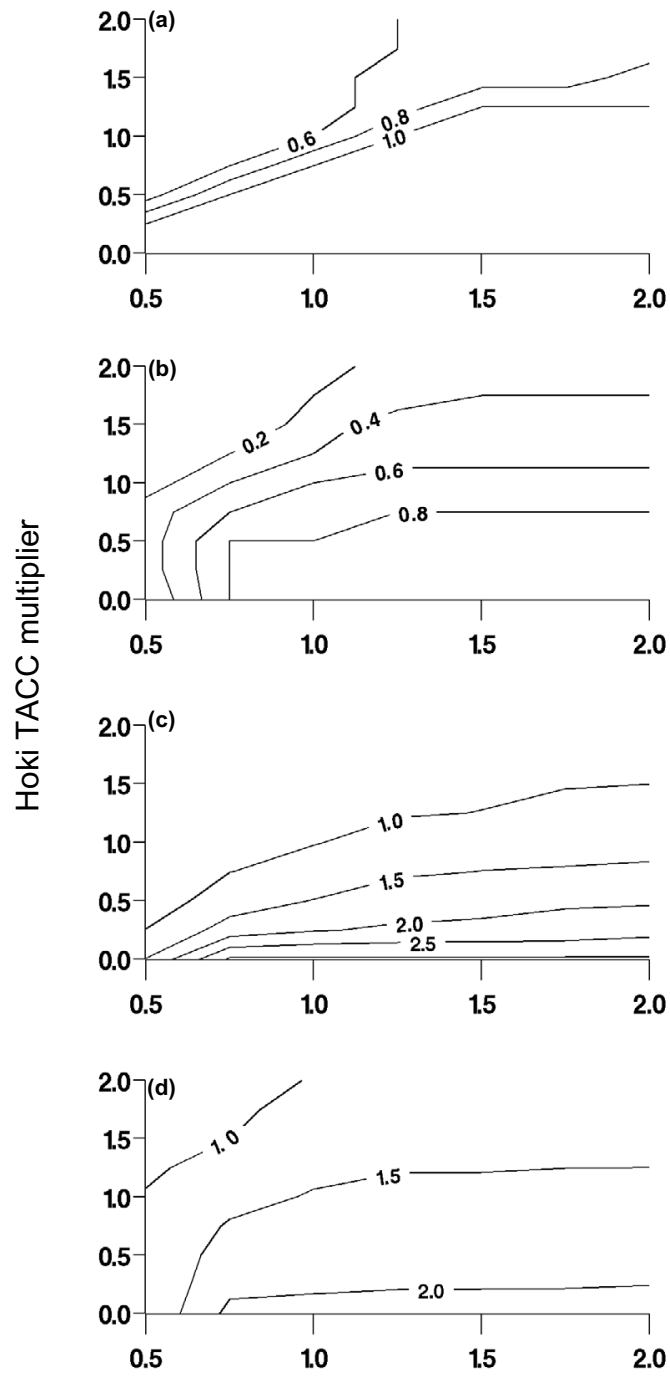

Hoki deemed value multiplier

Fig. 5. Changes in stock status indicators, resulting from changes in both the hoki deemed value and TACC: $(a, b)$ frequency of SSB exceeding $\mathrm{B}_{\mathrm{MSY}}$ over the 10-year projection period; (c, d) ratio between SSB and $\mathrm{B}_{\mathrm{MSY}}$ in the last projected year (year 10). The stocks shown are (a, c) Chatham Rise hake and (b, d) Western hoki. The spawning biomass of Sub-Antarctic hake, West Coast South Island hake and Eastern hoki always exceeds $\mathrm{B}_{\mathrm{MSY}}$ in the 10-year projection period, for all management strategies, and these stocks are not represented here.

building on recent assessments. One usual assumption made in these projections is that TACC cap perfectly future catches. The deemed value is a non-compliance penalty, which builds on the assumption that, in mixed-fisheries, the single-stock TACC may be exceeded. Let us consider the Western hoki stock, for example. Because that stock is currently considered depleted, it is necessary to decrease its current TACC to maintain it above $B_{\text {MSY }}$. The extent of that decrease, however, depends on deemed value-related compliance. We could see here that, by increasing the hoki deemed value, we could somehow limit the hoki TACC decrease compared to the option where the deemed value is unchanged. Reducing year-to-year
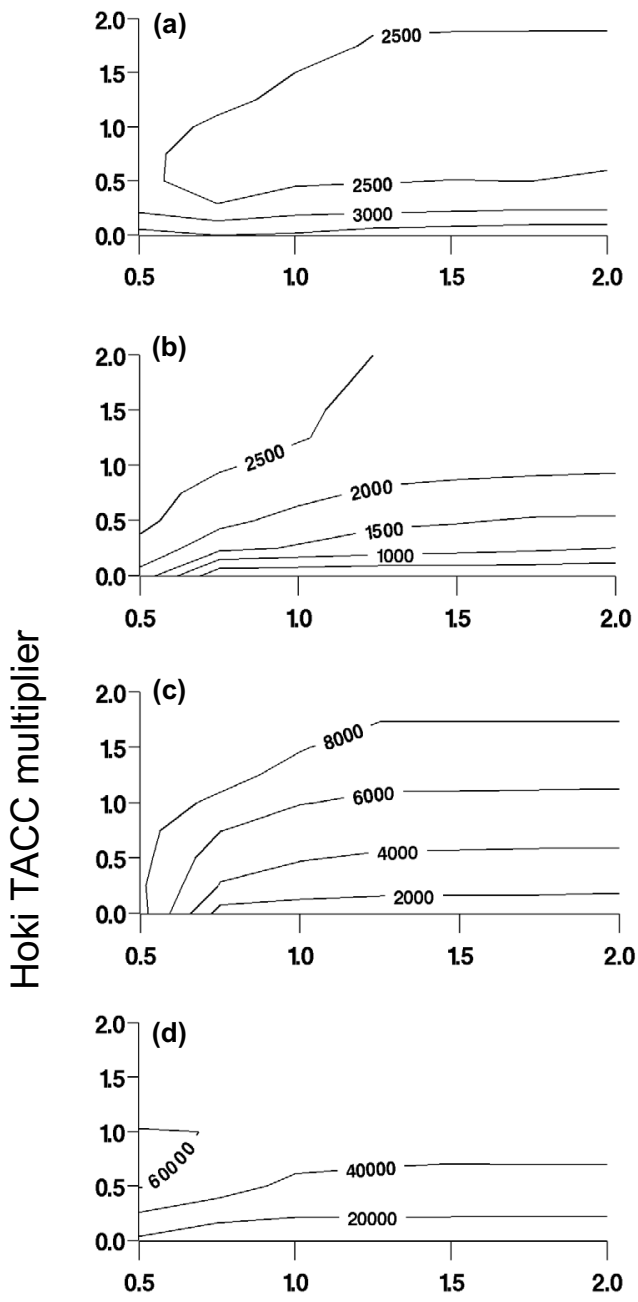

(e)

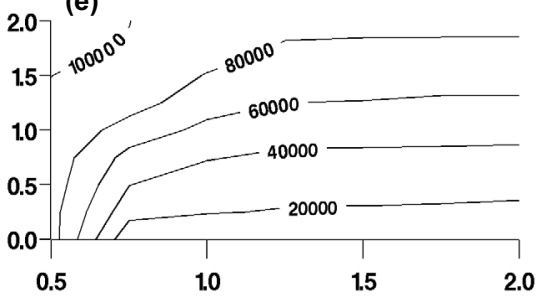

Hoki deemed value multiplier

Fig. 6. Changes in total catch $(\mathrm{t})$, averaged over the 10 -year projection period, resulting from changes in both the hoki deemed value and TACC. The stocks shown are (a) Sub-Antarctic hake, (b) Chatham Rise hake, (c) West Coast South Island hake, (d) Eastern hoki and, (e) Western hoki.

variations in TACC may be an attractive option for managers and stakeholders, and our investigation suggests that it might be achieved by setting the deemed value at appropriate levels.

Another important outcome of our investigation is that constraining hoki fishing (by either decreasing the hoki TACC or increasing the hoki deemed value) also restricts hake fishing in the Chatham Rise and in the West Coast South Island. This result indicates that it is more profitable for the modelled fleets 

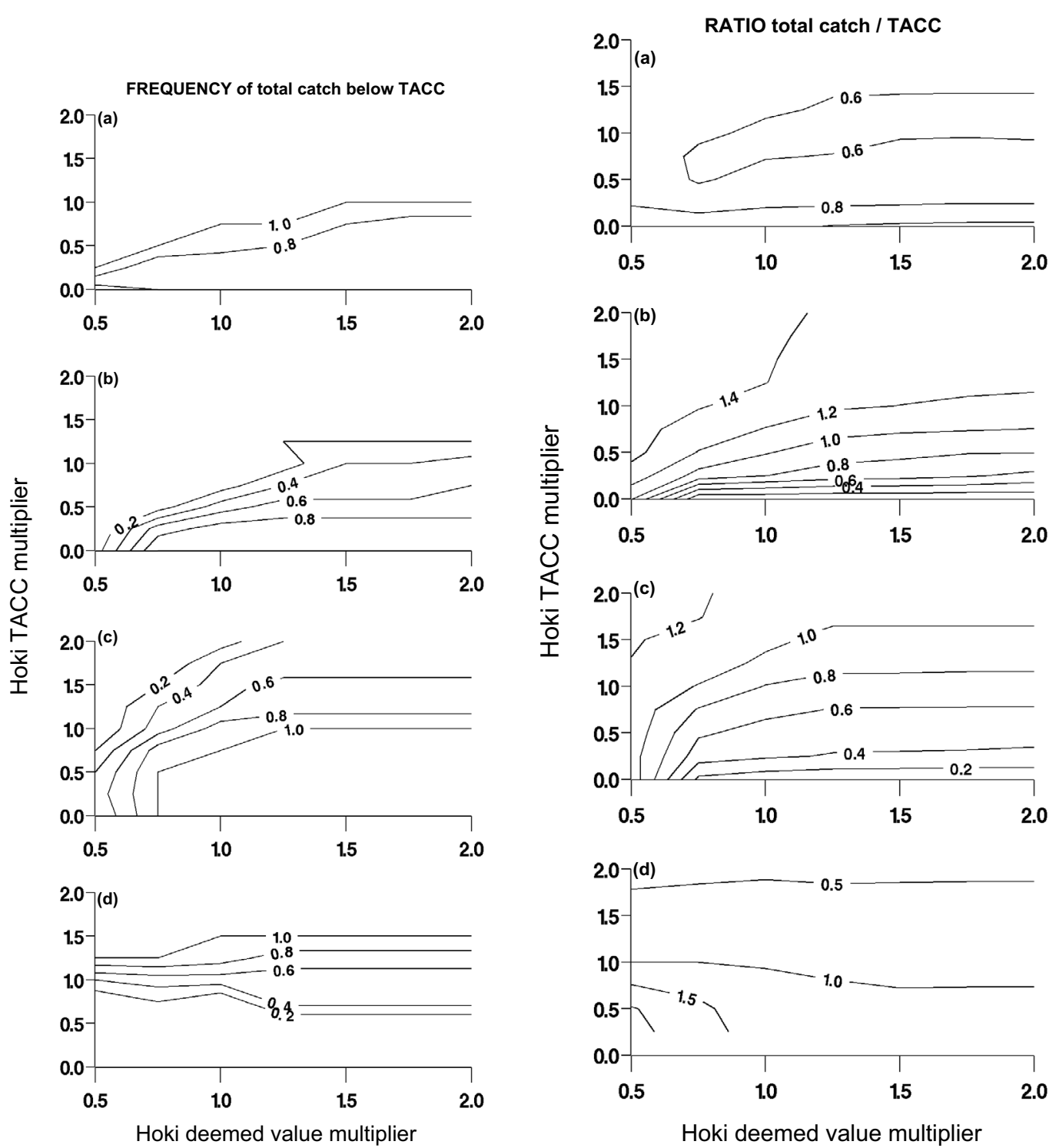

Fig. 7. Changes in the frequency of total catch below TACC (left hand side) and changes in the ratio between total catch and TACC (right hand side), averaged over the 10-year projection period, resulting from changes in both the hoki deemed value and TACC. The stocks shown are (a) Sub-Antarctic hake, (b) Chatham Rise hake, (c) West Coast South Island hake and, (d) Eastern hoki. The Western hoki catch always exceeds TACC, for all management strategies and projected years, and this stock is not represented here.

to reduce their overall fishing effort than to increasingly target these hake stocks as a result of the constraints applicable to the hoki fishery. The background of the finding is that the métiers operated in the Chatham Rise and in the West Coast South Island with a large hake target factor, also have a large hoki target factor (e.g., métiers 16, 13, 12 and 9 in Table 7). As a result, the fleets investigated here have only limited possibilities to target hake without catching substantial amounts of hoki. By contrast, decreasing the hoki TACC increases the targeting of Sub-Antarctic hake. In that area, fishing effort may be partly reallocated towards hake by increasingly operating métier $10^{1}$ as this métier ranks first as to hake fishing and operates with limited hoki by-catch. Our results also suggest that

${ }^{1}$ fishing non-spawning hoki in Sub-Antarctic area, FMA 5. this effort re-allocation would not compromise the sustainability of Sub-Antarctic hake for which the spawning biomass is above $B_{\mathrm{MSY}}$ for all management scenarios.

Our results also suggest that accompanying a reduction in the hoki TACC by an increase in the hoki deemed value would improve the sustainability of the mixed fishery whilst reducing year-to-year variations in TACC and catches, without necessarily changing the current hake TACC and deemed value. This is not to say, however, that combining these management measures would ensure perfect compliance with the TACC, even when the hoki deemed value is twice the current value. The rationale is that, in our model, fishing ceases only when the costs of paying ACE or deemed-value exceed the combined-species catch value which, as Figure 10 suggests, mainly occurs when 


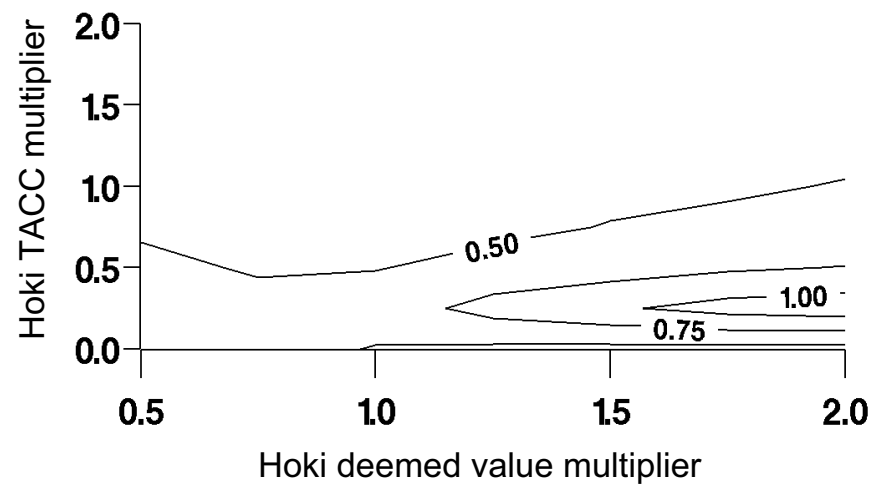

Fig. 8. Changes in the ratio between costs generated by ACE or deemed value payment and total value of the catches, averaged over the 10 -year projection.

the hoki TACC is at low level and when the hoki deemed value is more than 1.5 the current value.

Applying this modelling framework to different case studies may lead to different conclusions. Consider the European hake (Merluccius merluccius) and Norway lobster (Nephrops norvegicus) mixed-fishery in the Bay of Biscay, where haketargeting métiers may be distinguished from Norway lobstertargeting ones (Drouineau et al. 2006). For this case study, it could be investigated whether increasing the constraints on hake fishing would lead to a decrease in the overall fishing effort, an inflated re-allocation of fishing effort towards Norway lobster fishing, or both.

An important assumption made here was that the value of species other than hake and hoki is constant over time. However, other species (e.g. squid, barracuta, warehou, jack mackerel, ling, orange roughy) are believed to play an important role in the fishers' strategy and revenue. Including these species in our model could make some of the métiers more attractive, and in particular those métiers for which the hake and hoki target factors are relatively low. A result of this effort allocation shift could be an alleviation of the fishing pressure exerted on the hake and hoki stocks and, in particular, a prompter recovery of the western hoki stock. All these other stocks are regulated by TACC and deemed value, and could in principle be included in our analysis. There are also in principle no reasons for not including other components of the marine ecosystem potentially impacted by the hoki fishery in our analytical framework. These could include in particular New Zealand fur seals (Arctocephalus forsteri), for which sizeable by-catch occasionally occur in the West Coast South Island hoki fishery (Baird and Bradford 2000). New Zealand fur seal catches are capped by a maximum mortality rate. Although there were no provision for implementing such a management system at the time of writing, one could contemplate allotting the maximum mortality rate individually to fishers and to apply a deemed value to every animal caught above the limit. Apart from some added computational complexity, the main difficulty in accounting for all marine organisms impacted by the hoki fishery is that in most of the cases, little biological and assessment data are available, which adversely affect our ability to model analytically the fluctuations of the different species' biomass and catches. An alternative, perhaps more pragmatic, approach could be to model the dynamics of such data-poor species using simpler production or two-stage models, possibly by grouping these species by trophic level categories, similar to Laurec et al. (1991).

In our investigation, recruitment has been assumed constant for all stocks. Our sensitivity analysis suggested that both spawning biomass and catches were sensitive to recruitment levels, a usual feature in fishery science. Our conclusions built on a medium recruitment scenario, and we concluded that the SSB of three stocks (Eastern hoki, Sub-Antarctic hake, and West Coast South Island hake) would be above $B_{\mathrm{MSY}}$ for all management strategies. With lower recruitment levels, some of the management strategies (especially those with increased hoki TACC and lower hoki deemed value) could drive these stocks below $B_{\mathrm{MSY}}$.

Also in our model, the $B_{\text {MSY }}$ of both hoki stocks and of West Coast South Island hake were fixed rather arbitrarily. Some of our results (namely those related to the spawning biomass indicators) are sensitive to that choice, but the impact is rather straightforward as $B_{\mathrm{MSY}}$ was only used to calculate the spawning abundance indicators and not to parameterise the model itself. Basically, decreasing $B_{\mathrm{MSY}}$ would lead to higher SSB indicators for the stocks concerned and vice versa.

Finally, while the model allows for flexible effort allocation across métiers, the overall aggregate effort was constant over time, except when no expected profit could be made out of the hake and hoki catches. We could contemplate introducing a more flexible decision rule, which could reflect the decision to adapt not only the effort allocation among metiers, but also the overall level of fishing effort, to the expected profit.

An issue which remains pending is the rationale underlying the unstable catch oscillations observed with some management strategies (Fig. 4a). Other runs were carried out for various combinations of hoki TACC and deemed value and similar oscillations were observed for some of these. This result bears out the outcomes from a number of investigations which have evidenced that the outputs from simulated fisheries systems subject to complex regulation loops could be prone to unstable oscillation patterns (e.g., Horwood and Whittle 1986).

Future developments of the bio-economic model could include the implementation of (1) individual, transferable quota by fishing units, (2) the development of an effort allocation model based on a variety of alternative determinants other than VPUE, e.g. catch portfolios and traditions and, (3) adaptive management (Punt and Butterworth 1991; Marchal 1997).

Acknowledgements. This work was funded through the TRANZEF project (Transposing New Zealand fisheries management experiences to EU fleets and fisheries: a bio-economic modeling approach) by the European Union (contract no: MOIF-CT-2006-21646). The New Zealand Seafood Industry Council also provided assistance and funding. These supports are gratefully acknowledged. We are also indebted to Serge Garcia and anonymous refree for providing valuable comments on the first versions of this manuscript. 


\section{References}

Annala J.H., Sullivan K.J., Hore A.J., 1991, Management of multispecies fisheries in New Zealand by individual transferable quotas. ICES Mar. Sci. Symp. 193, 321-329.

Annala J.H., Sullivan K.J., Smith N.W.M., Griffiths M.H., Todd P.R., Mace P.M., Connell A.M., 2004, Report from the Fishery Assessment Plenary, April 2004: stock assessments and yield estimates. Unpublished report, NIWA library, Wellington.

Anonymous 2007, Report from the fishery assessment plenary, May 2007: stock assessments and yield estimates. New Zealand Ministry of Fisheries science group, pp. 322-343.

Arnason R., 2007, Advances in property rights based fisheries management: an introduction. Mar. Resour. Econ. 22, 335-346.

Baird S.J., Bradford E., 2000, Factors that may have influenced the bycatch of New Zealand fur seals (Arctocephalus forsteri) in west coast South Island hoki fishery. NIWA Tech. Rep. 92.

Branch T.A., Rutherford K., Hilborn R., 2006, Replacing trip limits with individual transferable quotas: implications for discarding. Mar. Policy 30, 281-292.

Bremner G., Johnstone P., Bateson T., Clarke P., 2009, Unreported by-catch in the West Coast South Island hoki fishery. Mar. Policy 33, 504-512.

Bull B., Francis R.I.C.C., Dunn A., McKenzie A., Gilbert D.J., Smith M.H., 2005, CASAL (C++ algorithmic stock assessment laboratory): CASAL user manual v2.07-2005/08/21. NIWA Tech. Rep. 127.

Caddy J.F., 1975, Spatial model for an exploited shellfish population, and its application to the Georges Bank scallop fishery. J. Fish Resour. Board Can. 32, 1305-1328.

Drouineau H., Mahévas S., Pelletier D., Beliaeff B., 2006, Assessing the impact of different management options using ISIS-Fish: the French Merluccius merluccius - Nephrops norvegicus mixed fishery of the Bay of Biscay. Aquat. Living Resour. 19, 15-29.

Dunn A., Ballara S.L., Phillips N.L., 2006, Stock assessment of hake (Merluccius australis) in HAK1 \& 4 for the 2004-2005 fishing year. New Zealand Fisheries Assessment Report 2006/11.

Francis R.I.C.C., 2007, Assessment of hoki (Macruronus novaezelandiae) in 2007. New Zealand Fisheries Assessment Report 2008/4.

Hentrich S., Salomon M., 2006, Flexible management of fishing rights and a sustainable fisheries industry in Europe. Mar. Policy 30, 712-720.
Hilborn R., 1985, Fleet dynamics and individual variation: why some people catch more than others. Can. J. Fish. Aquat. Sci. 42, 2-13.

Hilborn R., 2007, Managing fisheries is managing people: what has been learned. Fish Fish. 8, 285-296.

Holland D.S., 2000, A bio-economic model of marine sanctuaries on Gorges Bank. Canadian J. Fish. Aquat. Sci. 57, 1307-1319.

Horwood J.W., Whittle P., 1986, Optimal control in the neighbourhood of an optimal equilibrium with examples from fisheries models. IMA J. Math. Appl. Med. Biol. 3, 129-142.

Laurec A., Biseau A., Charuau, A., 1991, Modelling technical interactions. ICES Mar. Sci. Symp. 193, 225-236.

Mahévas S., Pelletier D., 2004, ISIS-Fish, a generic and spatiallyexplicit simulation tool for evaluating the impact of management measures on fisheries dynamics. Ecol. Model. 171, 65-84.

Marchal P., 1997, Managing growth overfishing with multiannual compromise strategies. Can. J. Fish. Aquat. Sci. 54, 2255-2276.

Pelletier D., Mahévas S., 2005, Fisheries simulation models for evaluating the impact of management policies, with emphasis on marine protected areas. Fish Fish. 6, 307-349.

Punt A.E., Butterworth D.S., 1991, On an approach for comparing the implications of alternative fish stock assessments, with application to the stock of Cape hake Merluccius spp. off northern Namibia. S. Afr. J. Mar. Sci. 10, 219-240.

Reeves S.A., Marchal P., Mardle S., Pascoe S., Prellezo R., Thébaud O., Travers M., 2008, From fish to fisheries : the changing focus of management advice. In: Payne A., Cotter J., Potter T. (Eds.) Advances in fisheries science 50 years on from Beverton and Holt, CEFAS, Blackwell Publishing, pp. 135-154.

Sanchirico J.N., Holland D., Quigley K., Fina, M., 2006, Catch-quota balancing in multispecies individual fishing quotas. Mar. Policy 30, 767-785.

Ulrich C., Andersen B.S., Sparre P.J., Nielsen J.R., 2007, TEMAS: fleet-based bio-economic simulation software to evaluate management strategies accounting for fleet behaviour. ICES J. Mar. Sci. 64, 647-651.

Walters C., Pauly D., Christensen, V., 1999, Ecospace: prediction of mesoscale spatial patterns in trophic relationship of exploited ecosystems with emphasis on the impacts of marine protected areas. Ecosystems 2, 539-554. 